\title{
MODEL KEPEMIMPINAN SEKOLAH KELAS MENENGAH MUSLIM DI
} YOGYAKARTA

\section{LEADERSHIP MODEL IN ISLAMIC SENIOR HIGH SCHOOL IN YOGYAKARTA}

\author{
Imam Machali \\ UIN Sunan Kalijaga Yogyakarta \\ Jl. Marsda Adisucipto Yogyakarta, 55281 \\ email: imam.machali@uin-suka.ac.id
}

Naskah Diterima: 30 Juli 2018; Direvisi: 15 November 2018; Disetujui: 01 Desember 2018

\begin{abstract}
School principal is the important key in leading Islamic educational institutions to improve and develop to be chosen by Islamic middle-class society as a place to educate their children. This research aimed to observe the leadership model of Islamic Senior High School Principal in Yogyakarta in improving, developing, and preserving the quality of Islamic educational institutions to be chosen by Islamic middle-class society in Yogyakarta. The results in this research explained that the leadership model in Islamic Senior High School is transformational leadership. This leadership model is established through two abilities possessed. First ability is knowledgeable, which means that a school principal is knowledgeable about the organizational theories, the organizational culture, the strategic management, the leadership, and other managerial knowledges. The wider knowledge and perspective a school principal has, the more open, flexible, inclusive, and open-minded the school principal is, to be able to manage a new knowledge. Second ability is experience, which is something that someone has encountered, undergone, endured, and borne. Experience is highly related with the ability and the will to continuously learn. The more opportunity to learn, the more experience will be achieved. The combination of knowledge and experience will establish a transformational leadership.
\end{abstract}

Keywords: Islamic middle-class; Leadership; Islamic school

\begin{abstract}
Abstrak
Kepala sekolah menjadi faktor kunci dalam membawa peningkatan dan perkembangan lembaga pendidikan Islam, sehiangga menjadi pilihan masyarakat kelas menengah Muslim untuk menyekolahkan pura putrinya. Penelitian bertujuan melihat bagaimana model kepemimpinan kepala sekolah kelas menengah muslim Yogyakarta dalam upaya meningkatkan, mengembangkan dan menjaga mutu lembaga pendidikan Islam sehingga menjadi sekolah pilihan masyarakat kelas menengah muslim di Yogyakarta. Hasil penelitian menunjukkan bahwa model kepemimpinan sekolah kelas menengah muslim adalah kepemimpinan transformasional. Model kepemimpinan ini terbentuk melalui dua kemampuan yang dimiliki yaitu, pertama, penguasaan pengetahuan (knowledge) seperti teori-teori organisasi, budaya organisasi, manajemen strategic, kepemimpinan, dan pengatahuan managerial lainnya. Semakin luas pengetahuan dan wawasan seseorang pemimpin, maka semakin terbuka, fleksibel, inklusif, mudah menerima masukan (open minded), dan mampu mengolahnya menjadi pengetahuan baru. Kedua adalah pengalamannya. Pengalaman adalah sesuatu yang pernah dialami, dijalani, dirasakan, ditanggung. Pengalaman sangat berhubungan dengan kemampuan dan kesediaan untuk terus belajar. Semakin banyak belajar, maka semakin banyak pula pengalaman yang akan didapat. Penggabungan antara pengetahuan dan pengelaman inilah yang akan membentuk kepemimpinan transformasional.
\end{abstract}

Kata kunci: Kelas menengah muslim; Kepemimpinan; Sekolah Islam 


\section{PENDAHULUAN}

Jumlah masyarakat kelas menengah di Indonesia terus meningkat. Berdasarkan data yang dikeluarkan oleh ADB menunjukkan bahwa pada tahun 1999, jumlah penduduk kelas menengah Indonesia sekitar 45 juta $(25 \%$ dari populasi), di tahun 2009 mencapai $57 \%$ dari populasi ${ }^{1}$ di tahun 2010 menjadi 134 juta dan pada tahun 2015 mencapai 170. Diperkirakan hingga tahun 2020 jumlah masyarakat menengah hingga 52\% dari total penduduk Indonesia. ${ }^{2}$ Jumlah ini hanya akan kalah dari negara China dan India. Badan Pusat Statistik menyebutkan juga diperkirakan persebaran penduduk daerah perkotan mencapai $60 \%{ }^{3}$ - sebagaimana yang didefinisikan Asia Development Bank-adalah masyarakat dengan rentang pengeluaran perkapita sebesar US\$2-20. Rentang pendapat tersebut dapat dibagi dalam dalam tiga kelompok, yaitu lower middle class, middle middle class dan upper middle class. lower middle class adalah masyarakat dengan pengeluaran perkapita sebesar US\$2-4, middle middle class adalah masyakat dengan pengeluaran perkapita sebesar US\$4-10, dan upper middle class dengan pengeluaran sebesar US\$10-20. ${ }^{4}$

Meningkatnya jumlah kelas menengah ini oleh berbagai faktor, diantaranya adanya impian menggapai kebebasan finansial, keinginan untuk melakukan pengelolaan aset (wealth management), gaya hidup virtual berupa internet yang mana kebutuhan tersebut

${ }^{1}$ Felia, Salim. (2012). Financial Club Discussion: Indonesia's Middle Class, p. 8.

${ }^{2}$ Hasanuddin, A., \& Purwandi, L. (2016). Indonesia 2020: The Urban Middle-Class Millenials. Alvara Research Center, Inc. Lebih lanjut juga lihat Hasanuddin Ali and Lilik Purwandi. (2017). Millennial Nusantara, Pahami Karakternya, Rebut Simpatinya. Jakarta: Gramedia, Inc.

${ }^{3}$ Anonim. (2012). Persentase Penduduk Daerah Perkotaan Menurut Provinsi, 20102035 https://www.bps.go.id/statictable/2014/ 02/18/1276/persentase-penduduk-daerah-perko taan-menurut-provinsi-2010-2035.html.

${ }^{4}$ Asian Development Bank. (2010). Key Indicators for Asia and the Pacific 2010. Philippines: Asian Development Bank, Inc. disalurkan melalui media sosial seperti whatsapp, twitter, instagram, facebook, dsb.

Meningkatnya jumlah masyarakat kelas menengah mengantarkan kepada era kelas menengah muslim yaitu penduduk Indonesia mayoritas beragama Islam dengan jumlah $88,2 \%$ dari penduduk Indonesia keseluruhan. Sehingga sebagian besar penduduk kelas menengah di Indonesia dapat dipastikan adalah Muslim, sehingga sebagian kelas menengah Indonesia adalah Muslim, atau yang biasa dikenal dengan Kelas Menengah Muslim Indonesia. Pada saat bersamaan, meningkatnya kelas menengah muslim ini diiringi dengan tumbuhnya lem-baga pendidikan dengan segmentasi kelas menengah muslim. Dalam berita yang pernah di post oleh NU Online Januari 2016 menyata-an bahwa Indonesia menjadi bangsa yang dikenal dengan banyaknya lembaga pendidikan Islam, bahkan jumlahnya menjadi terbesar di dunia. ${ }^{5}$

Berdasarkan data yang diperoleh dari BPS, jumlah sekolah meningkat dari tahun ke tahun. Tahun 2015/2016 total jumlah Madrasah Aliyah sejumlah 7.8436 , Madrasah Tsanawiyah $16.934^{7}$, dan Madrasah Ibtidaiyah

${ }^{5}$ Antara, \& Niam, M. (2016). Jumlah Lembaga Pendidikan Islam Di Indonesia Terbesar Di Dunia http://www.nu.or.id/post/ read/64871/jumlah-lembaga-pendidikan-Islamdi-indonesia-terbesar-di-dunia. Dikutip pada 25 November 2018

${ }^{6}$ Anonim. (2017). Jumlah Sekolah, Guru, Dan Murid Madrasah Aliyah (MA) Di Bawah Kementerian Agama Menurut Provinsi, Tahun Ajaran 2005/2006-2015/2016. https://www. bps.go.id/statictable/2014/09/10/1534/jumlahsekolah-guru-dan-murid-madrasah-aliyah-madi-bawah-kementerian-agama-menurut-provin si-tahun-ajaran-2005-2006-2015-2016.html. Dikutip pada 25 November 2018

${ }^{7}$ Anonim. (2017). Jumlah Sekolah, Guru, Dan Murid Madrasah Tsanawiyah (MTs) Di Bawah Kementrian Agama Menurut Provinsi Tahun Ajaran 2011/2012-2015/2016. https:// www.bps.go.id/statictable/2015/09/14/1836/ju mlah-sekolah-guru-dan-murid-madrasah-tsana wiyah-mts-di-bawah-kementrian-agama-menu rut-provinsi-tahun-ajaran-2011-2012-20152016.html. Dikutip pada 25 November 2018 
$24.560^{8}$. Jumlah ini belum termasuk kepada sekolah-sekolah Islam terpadu dan sekolahsekolah berbasis Islam lainnya.

Azyumardi Azra dan Jamhari dalam risetnya menyatakan bahwa dalam 10 tahun terakhir merupakan peluang sekaligus tantangan bagi dunia pendidikan Islam. Peluang, karena dalam masa-masa inilah kita menyaksikan meningkatnya "new attachment" kepada Islam di kalangan banyak masyarakat Muslim. Meningkatnya kecintaan kepada Islam ini membuat banyak kalangan orang tua, khususnya kalangan "kelas menengah" Muslim yang tengah tumbuh (Muslim rising middle class), semakin berusaha mendapatkan pendidikan Islam yang berkualitas bagi anak-anak mereka. Keinginan tersebut pada dasarnya adalah mendapatkan pendidikan umum Islam yang berkualitas tinggi, dimana peserta didik tidak hanya bergumul dengan ilmu-ilmu yang penting untuk kehidupan masa kini di dunia ini, tetapi juga ilmu-ilmu dan amal Islam. ${ }^{9}$

Bergesernya pilihan orang tua terhadap lembaga pendidikan Islam seperti sekolah, sekolah muhammadiyah dan sekolah Islam terpadu disebabkan karena orang tua (kelas menengah) lebih memilih menyekolahkan anaknya di sekolah yang memiliki dasar keagamaan dan keIslaman yang kuat dibanding sekolah umum. Hal ini berbanding terbalik dengan beberapa dekade sebelumnya, dimana orang tua dengan bangga menyekolahkan anaknya di sekolah-sekolah umum. ${ }^{10}$

${ }^{8}$ Anonim. (2017). Jumlah Sekolah, Guru, Dan Murid Madrasah Ibtidaiyah (MI) Di Bawah Kementrian Agama Menurut Provinsi Tahun Ajaran 2011/2012-2015/2016 URL https://www.bps.go.id/statictable/2015/09/10/1 811/jumlah-sekolah-guru-dan-murid-madrasah -ibtidaiyah-mi-di-bawah-kementrian-agamamenurut-provinsi-2011-2012-2015-2016.html. Dikutip pada 25 November 2018.

${ }^{9}$ Azyumardi Azra \& Jamhari. (2006). Pendidikan Islam Insonesia dan Tantangan Globalisasi: Prespektif Sosio-Historis. in Mencetak Muslim Modern: Peta Pendidikan Islam Indonesia, ed. Jajat Burhanuddin and Dina Afrianty. Jakarta: Rajawali Press, Inc.

${ }^{10}$ Suyatno. (2015). Integrated Islamic Primary School In The Middle-Class Muslims
Bahkan tiga varian lembaga pendidikan mainstream berupa sekolah, madrasah dan sekolah Islam telah bergeser dan berkembang. Pemetaan lembaga pendidikan dalam tiga varian tersebut saat sudah tidak relevan lagi. Saat ini terdapat beberapa lembaga pendidikan Islam yang membentuk varian baru, yang berbeda dengan varian sebelumnya. Munculnya model Sekolah Islam Terpadu (SIT) seperti SDIT, SMPIT, SMAIT, Sekolah Islam Berwawasan Internasional (SIBI), dan International Islamic School (Intis School) adalah bukti nyata bahwa terdapat varian baru dalam Lembaga Pendidikan Islam. ${ }^{11}$ Nurhaidi memandang bahwa pergeseran dominasi lembega pendidikan Islam mainstream seperti tersebut disebabkan hadirnya sekolah Islam Terpadu $^{12}$. Hingga 2013, jumlah sekolah yang berada dalam Jaringan Sekolah Islam Terpadu (JSIT) Indonesia mencapai 1.926 unit sekolah. Yakni terdiri atas 879 unit TK. 723 unit SD, 256 unit SMP, dan 68 unit SMA. ${ }^{13}$ Usamah Hisyam menuturkan jumlah sekolah Islam terpadu telah mencapai 10.000 sekolah di seluruh Indonesia dari tingkat TK hingga SMU.

Meningkat dan berkembangnya sekolahsekolah Islam sehingga menjadi pilihan orang tua kelas menengah Muslim dalam menyekolahkan pura putrinya tidak lepas dari peran kepemimpinan kepala sekolah. Kepala sekolah menjadi faktor kunci dalam membawa peningkatan dan perkembangan lembaga pendidikan. Fungsi kepala sekolah sebagai

Indonesia Conception. Analisa 22(1): 122, https://doi.org/10.18784/analisa.v22i1.148.

${ }^{11}$ Machali, I. (2015). Rethinking Marketing Madrasah: Menimbang Pola Dan Strategi Pemasaran Jasa Pendidikan Madrasah. EDUKASI: Jurnal Penelitian Pendidikan Agama dan Keagamaan, 13(1): 6

${ }^{12}$ Hasan, N. (2009). Islamizing Formal Education: Integrated Islamic School and a New Trend in Formal Education Institution in Indonesia With Compliments. p. 5.

${ }^{13}$ Heri Ruslan. (2014). 10 Tahun JSIT Indonesia Bangun Pendidikan Lewat SIT URL https://www.republika.co.id/berita/pendidikan/ eduaction/14/01/31/n08dcm-10-tahun-jsit-indo nesia-bangun-pendidikan-lewat-sit. Dikutip pada 25 November 2018 
educator, motivator, administrator, supervisor, leader, Innovator dan manager menjadi fungsi kunci kemajuan lembaga pendidikan Islam.

Pelelitian ini bermaksud melihat bagaimana model kepemimpinan kepala sekolah kelas menengah muslim Yogyakarta dalam upaya meningkatkan, mengembangkan dan menjaga mutu lembaga pendidikan Islam sehingga menjadi sekolah pilihan masyarakat kelas menengah muslim di Yogyakarta.

\section{METODOLOGI PENELITIAN}

Paradigma dalam penelitian ini adalah penelitian kualitatif. Data dikumpulkan dengan menggunakan teknik observasi, wawancara, dan dokumentasi. Observasi dilakukan di sekolah-sekolah kelas menengah muslim Yogyakarta. Peneliti mengamati kegiatan dan aktivitas yang dilakukan oleh kepala sekolah. Selain itu peneliti juga mengamati programprogram yang diinisiasi oleh kepala sekolah. Wawancara digunakan untuk mendapatkan data yang diinginkan, wawancara dilakukan dengan menggunakan pedoman wawancara. Dokumen yang menjadi data penelitian adalah teks, arsip, catatan, buku, dan foto yang memberikan informasi visual tentang kegiatan sekolah kelas menengah muslim di Yogyakarta. Wawancara dan dokumentasi dipergunakan untuk memperoleh data dan informasi yang saling menunjang dan melengkapi dalam penelitian model kepemimpinan sekolah kelas menengah muslim di Yogyakarta.

Uji keabsahan data dalam penelitian ini dilakukan dengan cara melakukan observasi lebih lama dengan memperhatikan intensitas interaksi dengan informan untuk menghindari biasnya data dan menguji secara trianggulasi. Teknik analisis data dengan menggunakan alur kegiatan seperti yang dikemukakan oleh Miles dan Haberman $(1994,21)$ yaitu data reduction, data display and conclusion drawing/ verivication. ${ }^{14}$

Pengumpulan data tentang model kepemimpinan sekolah kelas menengah muslim

${ }^{14}$ Matthew B. Miles \& A. Michel Huberman. (1992). Analisis Data Kualitatif. Terj. Tjetjep Rohendi Rohidi. Jakarta: UI Press. Inc. di Yogyakarta dilakukan melalui pengamatan, wawancara dan dokumentasi. Data-data yang diperoleh tersebut kemudian direduksi dan diseleksi sesuai dengan kebutuhan pemecahan masalah penelitian. Setelah direduksi, kemudian ditentukan komponen yang terfokus untuk diamati dan diwawancara, yaitu mengenai model kepemimpinan sekolah kelas menengah muslim di Yogyakarta. Hasil wawancara dan pengamatan kemudian direduksi kembali dan diarahkan untuk menjawab masalah penelitian yang telah dirumuskan. Langkah berikutnya adalah menyederhanakan menyusun secara sistematik hal-hal yang pokok dan penting dan membuat abstraksi untuk memberi gambaran yang tepat, kemudian ditarik sebuah kesimpualan.

\section{HASIL DAN PEMBAHASAN}

\section{Kepemimpinan Sekolah}

Kepala sekolah dalam satuan pendidikan merupakan pemimpin, ia mempunyai dua jabatan dan peran penting dalam melaksanakan proses pendidikan. Pertama, kepala sekolah adalah pengelola pendidikan di sekolah, dan kedua, kepala sekolah adalah pemimpin formal pendidikan di sekolahnya.

Sebagai pengelola pendidikan, kepala sekolah bertanggung jawab terhadap keberhasilan penyelenggaraan kegiatan pendidikan dengan cara melaksanakan administrasi sekolah dengan seluruh substansinya. Di samping itu, kepala sekolah bertanggung jawab terhadap kualitas sumber daya manusia yang ada agar mereka mampu menjalankan tugas-tugas pendidikan. Oleh karena itu sebagai pengelola, kepala sekolah memiliki tugas untuk mengembangkan kinerja para personal (terutama para guru) kearah profesionalisme yang diharapkan.

Sebagai pemimpin formal, kepala sekolah bertanggung jawab atas tercapainya tujuan pendidikan melalui upaya menggerakan para bawahan ke arah pencapaian tujuan pendidikan yang telah ditetapkan. Dalam hal ini kepala sekolah bertugas melaksanakan fungsi-fungsi kepemimpinan, baik fungsi yang berhubungan dengan pencapaian tujuan pendidikan maupun penciptaan iklim dan budaya sekolah yang konduktif bagi 
terlaksananya proses belajar mengajar secara efektif, efisien dan produktif.

Kepala sekolah sebagai pemimpin pendidikan setidaknya harus memiliki kompetensi dasar manajerial yaitu pertama, keterampilan teknis (technical skill). Keterampilan ini berhubungan dengan pengetahuan, metode dan teknik-teknik tertentu dalam menyelesaikan suatu tugas-tugas tertentu. Dalam prakteknya, keterlibatan seorang pemimpin dalam setiap bentuk technical skill disesuaikan dengan tingkatan pemimpin itu sendiri. Kedua, keterampilan manusiawi (human skill). Keterampilan ini menunjukkan kemampuan seorang pemimpin di dalam bekerja melalui orang lain secara efektif, dan untuk membina kerjasama. Dan ketiga keterampilan konseptual (conceptual skill). Keterampilan ini menunjukkan kemampuan dalam berfikir, seperti menganalisa suatu masalah, memutuskan dan memecahkan masalah tersebut dengan baik. Untuk dapat menerapkan keterampilan ini seorang pemimpin dituntut memiliki pemahaman yang utuh (secara totalitas) terhadap organisasinya. Tujuannya agar ia dapat bertindak selaras dengan tujuan organisasi secara menyeluruh atas dasar tujuan dan kebutuhan kelompok sendiri. ${ }^{15}$

Fungsi kepemimpinan Sekolah memiliki dua dimensi, yaitu: pertama, dimensi yang berkenaan dengan tingkat kemampuan mengarahkan (direction) dalam tindakan atau aktivitas pemimpin. Kedua, dimensi yang berkenaan dengan tingkat dukungan (support) atau keterlibatan orang-orang yang dipimpin dalam melaksanakan tugas-tugas pokok kelompok atau organisasi. ${ }^{16}$

Terkait dengan fungsi kepemimpinan sekolah setidaknya mencakup tujuh fungsi pokok sebagaimana yang dikenal dengan akronim EMASLIM (educator, manager,

${ }^{15}$ Iskandar, J. (2017). Keterampilan Manajerial Kepala Sekolah, Jurnal Idaarah, 1(1): 89-95.

${ }^{16}$ Junaidah. (2015). Kontribusi Pemimpin Pendidikan Dalam Meningkatkan Mutu Pendidikan Di Perguruan Tinggi. Al-Idarah: Jurnal Kependidikan Islam, 5(2): 92. https://doi.org/10.24042/ALIDARAH.V5I2.78 4. administrator, supervisor, leader, innovator, dan motivator). ${ }^{17}$

Pertama, Kepala Sekolah sebagai Pendidik (Educator). Edukator atau pendidik adalah orang yang bertanggungjawab terhadap upaya perkembangan jasmani dan rohani peserta didik agar mencapai tingkat kedewasaan sebagaimana tujuan pendidikan. Dalam Sistem Pendidikan Nasional educator atau Pendidik diartikan sebagai tenaga kependidikan yang berkualifikasi sebagai guru, dosen, konselor, pamong belajar, widyaiswara, tutor, instruktur, fasilitator, dan sebutan lain yang sesuai dengan kekhususannya, serta berpartisipasi dalam menyelenggarakan pendidikan.

Kedua, kepala sekolah sebagai manajer (manager). Kepala sekolah sebagai manajer mempunyai tugas dan tanggungjawab merencanakan, mengorganisasikan, mengkoordinasikan, dan mengontrol sumber-sumber sekolah yang ada untuk melaksanakan program pendidikan secara efektif, efisien dan produktif. Sebagaimana dengan peran dan tugas-tugasnya sebagai manajer, kepala sekolah dituntut untuk dapat menciptakan manajemen sekolah yang efektif, efisien dan produktif.

Ketiga, kepala Sekolah sebagai administrator. Kepala Sekolah sebagai administrator mempunyai tugas-tugas antara lain: melakukan perencanaan, pengorganisasian, pengarahan, pengkoordinasian, pengawasan terhadap berbagai bidang yang menunjang pendidikan seperti; kurikulum, kesiswaan, kantor, kepegawaian, perlengkapan, keuangan, dan perpustakaan. Dengan demikian, kepala sekolah sebagai administrator berarti harus menjalankan seluruh kegiatan administrasi sekolah, dan bertanggung jawab atas terlaksananya seluruh kegiatan administrasi di sekolah.

Keempat, kepala sekolah sebagai supervisor. Kepala sekolah sebagai supervisor berarti harus mampu melakukan peran-peran supervisi pada seluruh kegiatan yang ada di

${ }^{17}$ Machali, I., \& Hidayat, A. (2018). The Handbook of Education Management, Teori dan Praktik Pengelolaan Sekolah/Madrasah di Indonesia. Jakarta: Prenadamedia Group, Inc. 
sekolah, dan melakukan kontrol agar seluruh kegiatan dapat berjalan secara efektif, efisien dan produktif.

Kelima, kepala sekolah sebagai leader. Kepala sekolah sebagai pemimpin sekolah memiliki tanggung jawab menggerakkan seluruh sumberdaya yang ada di sekolah sehingga melahirkan etos kerja dan produktivitas yang tinggi dalam mencapai tujuan pembelajaran. Oleh karena itu, kepala sekolah dalam menjalankan fungsi ke-pemimpinannya harus menetapkan garis-garis besar kebijakan, program dan kegiatan-kegiatan operasional, dan kepala sekolah bertanggung jawab atas terlaksananya seluruh kebijakan tersebut.

Keenam, kepala sekolah sebagai innovator. Kepala sekolah sebagai inovator adalah pribadi yang dinamis dan kreatif, selalu mengembangkan diri untuk kemajuan sekolah. Sebagai innovator, kepala Sekolah harus mampu menemukan inovasi-inovasi baru dalam pembelajaran. Oleh karena itu, kepala sekolah sebagai inovator harus mampu menemukan gagasan-gagasan baru sesuai dengan perkembangan lingkungan internal dan eksternal, perkembangan ilmu pengetahuan dan teknologi serta kebutuhan peserta didik. Disamping itu, kepala sekolah juga harus melakukan pembaharuan di sekolah agar sekolah senantiasa berkembang mengikuti perkembangan iptek. Kepala Sekolah harus menjadi agen pembaharuan.

Ketujuh, kepala sekolah sebagai motivator. Sebagai motivator, kepala sekolah harus senantiasa memberikan motivasi dan dorongan kepada semua pihak untuk maju, berkembang sesuai dengan keinginan individu, dan berkembang guna memajukan sekolah. ${ }^{18}$

\section{Kelas Menengah Muslim}

Pengertian Kelas menengah secara umum didefinisikan melalui dua pendekatan yaitu pendekatan absolut dan relatif. Melalui pendekatan absolut, Lester Thurow mendefinisikan kelas menengah Amerika Serikat

${ }^{18}$ Imam Machali \& Ara Hidayat. (2018). The Handbook of Education Management, Teori dan Praktik Pengelolaan Sekolah/Madrasah di Indonesia. Jakarta: Prenadamedia Group, Inc. sebagai kelompok masyarakat yang memiliki rentang pendapatan sebesar $75 \%$ (untuk batas bawah-floor) dan $125 \%$ (untuk batas atas) dari median pendapatan perkapita. ${ }^{19}$ Easterly dari New York University mengemukakan bahwa keberadaan kelas menengah yang cukup besar dan relatif makmur secara signifikan berkorelasi dengan pertumbuhan jangka panjang. Eastley mendefinisikan kelas menengah dengan membagi penduduk ke dalam empat kelompok consumtion expenditure (pengeluaran konsumsi) yang sama (quintiles), dari kelompok masyarakat termiskin hingga terkaya. Pengertian Kelas menengah diperoleh dengan mengeluarkan quantiles terbawah (20\% kelompok masyarakat termiskin) dan quantiles teratas $(20 \%$ kelompok masyarakata terkaya), sehingga kelas menengah didefinisikan sebagai kelompok masyarakat yang memiliki pengeluaran perkapita di quantiles kedua, ketiga, dan keempat. ${ }^{20}$

Asia Development Bank (ADB) mendefinisikan kelas menengah dengan rentang pengeluaran perkapita sebesar US\$2-20, yang mana rentang tersebut di bagi lagi ke dalam 3 kelompok, yaitu lower, middle dan upper middle class. Untuk pengeluaran perkapita lower middle class sebesar US\$2-4, untuk middle middle class sebesar US\$4-10, dan sebesar US\$10-20 untuk upper middle class. Definisi ini lebih cocok untuk Negara-negara Asia. $^{21}$

Penduduk Indonesia sebagian besar adalah beragama Islam dengan jumlah 88,2 \% dari penduduk Indonesia keseluruhan.

${ }^{19}$ OECD. (2010). Latin American Economic Outlook 2011: How Middle Class Is Latin Amerika? France: OECD Publishing, Inc.

${ }^{20}$ OECD. (2010). Latin American Economic Outlook 2011: How Middle class is latin amerika? France: OECD Publishing, Inc. Penjelasan secara rinci dapat dilihat pada William Easterly, The Middle Class Consensus And Economic Development, World bank. July 2001

${ }^{21}$ Asian Development Bank. (2010). Key Indicators for Asia and the Pacific 2010, Mandaluyong City, Philippines: Asian Development Bank, Inc. 
Sehingga sebagian besar penduduk kelas menengah di Indonesia juga dapat dipastikan adalah Muslim.

\section{Kelompok Kelas Menengah Muslim}

Penjelasan tentang kelompok kelas menengah ini diungkapkan dalam penelitian Yuswohady tentang 8 wajah kelas menengah Indonesia. $^{22}$ Pola konsumsi masyarakat menengah Indonesia semakin meningkat terhadap beberapa hal, diantaranya gaya hidup digital (internet), pengelolaan aset, mencapai kebebasan finansial, hiburan, dan lembaga pendidikan pilihan. Terdapat 8 wajah kelas menengah Indonesia yang diperoleh dari tiga dimensi segmentasi dalam memetakan nilainilai, sikap dan perilaku. Tiga dimensi segmentasi tersebut adalah ownership of resources, knowledgeability, dan social connection.

\section{Dimensi ownership of resources,} menggambarkan tingkat sumber daya yang dimiliki terutama sumber daya finansial yang memengaruhi kemampuan daya beli dan konsumsi terhadap berbagai barang dan jasa. Besar kecilnya sumber daya yang dimiliki seseorang mencerminkan tingkat hidup (standard of living). Masyarakat kelas menengah umumnya diidentikkan dengan kelompok masyarakat yang sudah memiliki standar hidup lumayan karena memiliki aset finansial yang cukup signifikan seperti penghasilan tiap bulan, rumah, mobil, barangbarang rumah tangga (TV, lemari es, AC, mesin cuci, dsb), tabungan, atau instrumen investasi seperti emas, saham, atau reksadana.

Dimensi knowledgeability, menggambarkan tingkat pengetahuan, wawasan, keterbukaan pikiran, adopsi informasi dan teknologi, visi dan tujuan hidup (vision and sense of purpose), penerimaan terhadap modernisasi dan nilai-nilai universal, dan lainlain. Meningkatnya pengetahuan dan wawasan melalui pendidikan secara mendasar akan mendorong keterbukaan intelektual (intellectual openess), fleksibilitas, dan keluasan pandangan yang pada gilirannya akan

${ }^{22}$ Yuswohadi \& Kemal E Gani. (2015). 8 Wajah Kelas Menengah, Jakarta: Gramedia, Inc. mendorong terbentuknya nilai-nilai kemandirian (self-direction values). Tingkat pengetahuan yang tinggi dan terbukanya wawasan seseorang akan berpengaruh secara mendasar pada pola pikir dan orientasi hidup seseorang. Hal ini pada gilirannya akan memengaruhi nilainilai yang dianut dan perilaku-perilakunya.

Dimensi social connection, menggambarkan tingkat keterhubungan seseorang dengan lingkungan sosialnya. Lingkungan sosial ini mencakup unit yang paling kecil yaitu keluarga dan tetangga, lingkungan masyarakat yang lebih luas seperti negara, hingga lingkungan masyarakat global/ universal. Dimensi ini mencerminkan seberapa besar seseorang memengaruhi dan dipengaruhi lingkungan sosialnya. Perkembangan teknologi online yang berlangsung secara masif selama sepuluh tahun terakhir ini membawa perubahan besar yang belum pernah ada dalam kemajuan umat manusia sebelumnya. Selanjutnya Yuswohadi dan Kemal E Gani dalam penelitiannya memetakan 8 wajah kelas menengah yang disajikan pada Gambar 1 .

Expert, kebanyakan adalah profesional di berbagai bidang mulai dari dokter, arsitek, konsultan, atau pengacara yang selalu berupaya menjadi ahli di bidang yang digelutinya. Setiap hari mereka sibuk menekuni bidang profesinya dari pagi hingga larut malam. Karena "tertawan" oleh perkerjaan, mereka tidak memiliki cukup waktu luang untuk anak-anak, jalan-jalan di mal, atau menghadiri acara keluarga/kerabat. Karena itu, lingkungan pergaulan mereka juga terbatas di lingkungan profesinya. Intinya, "their life is their career".

Climber adalah para pegawai pabrik (blue collar), salesman, supervisor, dan sebagainya yang berupaya keras membantingtulang untuk menaikkan status ekonominya. Harapan utama mereka adalah mendongkrak karier dan menaikkan taraf kehidupan menjadi lebih baik. Karena umumnya masih mengawali karier, mereka masih suka pindah-pindah kerja (job-hunter), risk-taker dalam karier, dan cenderung melihat bahwa "career is a journey". Umumnya mereka memiliki familyvalues yang tinggi dan bekerja keras untuk keluarga. Karena itu, mereka adalah sosok "hero of their family". 


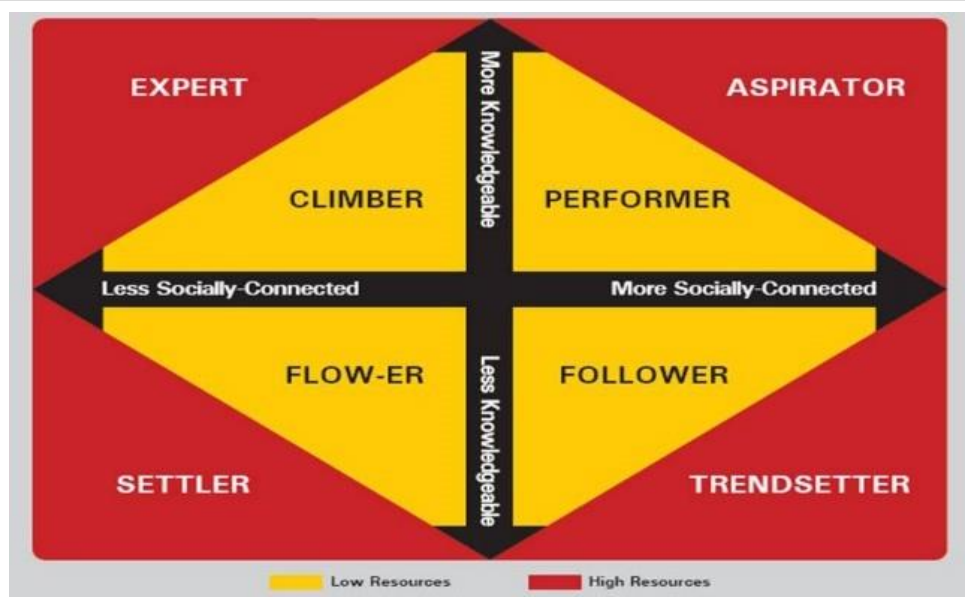

Gambar 1. Pemetaan 8 wajah kelas menengah

Sumber: Yuswohadi dan Gani, 2015: 70

Aspirator adalah performer yang sudah mapan dan cukup puas dengan kondisi ekonomi saat ini, mereka juga open mind terhadap globalisasi dan mengadopsi nilai-nilai universal. Karena sudah merasa cukup, orientasi hidup mereka tidak lagi hanya memikirkan diri sendiri (selfish), akan tetapi mulai memikirkan hal-hal di luar dirinya seperti mulai peduli dengan pemanasan global atau kebakaran hutan Kalimantan, dan lainlain. Ia punya harapan menjadi influencer bagi masyarakat, lingkungan, dan negaranya.

Performer adalah kalangan profesional dan enterpreneur yang memiliki ambisi luar biasa untuk membangun kompetensi diri. Mereka adalah self-achiever yang menggunakan kompetensi dan keterampilan sebagai alat untuk mendongkrak tingkat ekonomi. Karena itu, mereka selalu meng-update informasi, mengadopsi teknologi, dan terus belajar untuk meng-improve diri. Performer lebih ambisius terhadap diri sendiri dengan misi hidup mencapai kebebasan keuangan (financial freedom) karena mereka belum puas dengan tingkat kehidupan ekonomi saat ini.

Trend-setter memiliki daya beli yang lebih tinggi (more resource) dibanding follower. Karena lebih mampu, mereka ingin menjadi panutan dalam gaya hidup (peripheral lifestyle) seperti fashion, gaya selebriti, gadget, dan sebagainya bagi teman-temannya. They are victim of trends. Untuk bisa terus mengikuti tren dan isu-isu tebaru, mereka aktif berkoneksi di lingkungan teman-temannya menggunakan facebook atau twitter. Dengan karakteristik tersebut, mereka adalah orang- orang narsis (narcissist) dan cenderung selfcentered.

Follower umumnya adalah kalangan muda (SMA dan kuliah) yang membutuhkan panutan (role model) untuk menemukan dan menunjukkan eksistensinya karena mereka masih mencari jati diri, belum punya banyak pengalaman, dan wawasannya masih terbatas (short-term vision, less sense of purpose). Bagi mereka teman adalah segalanya (friends are everything) dan diterima di lingkungan teman merupakan sesuatu yang penting untuk menunjukkan eksistensi mereka.

Settler adalah flow-er yang sudah memiliki kemapanan hidup. Sosok ini merintis warung atau punya lahan luas hasil warisan yang menghasilkan sumber keuangan cukup besar bagi kehidupan ekonomi. Karena tingkat pengetahuan yang terbatas, maka mereka cenderung memegang nilai-nilai tradisional dan fobia terhadap perkembangan informasi, teknologi, dan globalisasi. Karena sudah puas dengan sukses yang dicapai saat ini, mereka cenderung tidak belajar dan mengembangkan diri. They are at the comfort zone.

Flow-er adalah sosok yang tidak puas dengan tingkat kehidupan ekonominya saat ini, namun mereka tidak tahu harus bagaimana untuk mengubahnya. Karena tingkat pendidikan dan pengetahuan yang terbatas, mereka cenderung kurang memperbaharui informasi dan mengadopsi teknologi sehingga wawasan dan visi hidupnya terbatas. Dengan keterbatasan itu, hidup mereka cenderung pasrah dan mengalir (flow) di tengah perubahan kehidupan (teknologi, informasi, sosial, politik, 
dsb) yang cepat dan bergolak. Di tengah pergolakan hidup yang cepat, pegangan mereka hanya satu, yaitu keyakinan agama (high spiritual values). Karena itu, mereka cenderung menyeimbangkan kehidupan dunia dan akhirat.

\section{Kepemimpinan Sekolah Kelas Menengah Yogyakarta}

Maju dan berkembangnya sekolah kelas menengah muslim di Yogyakarta tidak lepas dari modal dan sumber daya yang dimiliki. Modal dan sumber daya sekolah atau yang disebut dengan stakeholder sekolah adalah semua komponen sekolah baik internal maupun ekternal yang menjadi penopang berjalannya proses pembelajaran. Yayasan, kepala sekolah, guru, siswa, dan staf administrasi adalah stakeholder internal. Sedangkan orang tua wali, pengguna, dinas pendidikan adalah stakeholder eksternal sekolah. Semua komponen stakeholders tersebut menopang dan mendukung terlaksananya proses pembelajaran.

Dari segi segmentasi pasar, sekolah kelas menengah muslim yogyakarta membidik target pasar kelas menengah baik baik lower middle class, middle middle class dan upper middle class. Pasar kelas menengah ini sebagian besar adalah masuk dalam katagori pasar rasional. Pasar rasional adalah pelanggan atau "nasabah" sekolah yang benar-benar sensitif terhadap perkembangan dan kualitas mutu pendidikan. Menurut mereka, pendidikan yang berkualitas dan bermutu baik adalah pendidikan yang menyesuaikan diri dengan perkembangan zaman, muatan pelajaran yang bertaraf internasional, penggunaan bahasabahasa global (Inggris), dan didukung oleh fasilitas dan jaringan (networking) memadai. ${ }^{23}$ Selain pasar rasional tersebut juga ada yang termasuk dalam katagori pasar rasioemosional. Pasar rasio-emosional adalah kumpulan pelanggan atau "nasabah" yang datang mendaftar atau bergabung ke sebuah lembaga pendidikan (sekolah) disamping

${ }^{23}$ Imam Machali dan Ara Hidayat. The Handbook of Education Management, Teori dan Praktik Pengelolaan Sekolah/Madrasah di Indonesia. (Jakarta: Prenadamedia Group, 2016), hlm. 296 pertimbangan rasional-benar-benar sensitif terhadap perkembangan dan kualitas mutu Pendidikan-meraka sangat mempertimbangkan aspek religiousitas. Pembinaan Islamkeagamaan, akhlak, dan muatan pelajaran agama menjadi salah satu pertimbangan penting dalam menentukan sekolah.

Kelas menengah muslim ini pada umumnya sangat perhatian dan meganggap penting terhadap pendidikan anak-anaknya, mereka secara ekonomi sudah mulai tercukupi atau mapan, sehingga tidak begitu mempertimbangkan biaya sekolah putraputrinya. "asalkan sekolah memberikan fasilitas memadai, proses pembelajaran yang baik dan berkualitas sesuai yang diharapkan, maka berapun akan dibayar". Aspek pasar kelas menengah muslim dan sengmentasi rasional dan rasio-emosional ini menjadi modal utama kepala sekolah dalam mengembangkan lembaga pendidikannya. Kemudahan pembiayaan dari wali murid terbukti lebih mudah bagi pengelola sekolah untuk mengembangkan daripada yang sulit pembiayaannya. Kepala sekolah bebas melakukan inovasi dan bereksperimentasi melakukan kegiatan-kegiatan pendukung dan penunjang untuk kualitas pembelajaran sekolah. Berangkat dari sini maka model kepemimpinan sekolah dapat dikelompokkan menjadi empat bagian yaitu, transformation, intruction, direction, dan sceptic. Keempat model kepemimpinan tersebut dibangun berdasarkan modal pengetahuan yang dimiliki (knowledge skills) dan pengalaman (experience). Modal pengetahuan dan pengalaman tersebut akan membentuk model kepemimpinan sebagaimana dalam Gambar 2.

Pada kuadran pertama adalah
transformation leader atau pemimpin
transformasi. Transformation leader terbentuk
dari pengausaan pengetahuan (knowledge) dan
pengalaman memimpin (experience).
Penguasaan pengetahuan seperti teori-teori organisasi, budaya, dan pengetahuan bidang yang dipimpin menjadi factor penting dalam sukses memimpin. Semakin meningkat pengetahuan dan wawasan akan mendorong keterbukaan, fleksibilitas, dan keluasan pandangan yang akan mendorong terbentuknya kepemimpinan yang baik. Sedangkan 
pengalaman adalah sesuatu yang membentu kepribadian seseorang sehingga mengetahui secara praktis apa yang dilakukan. Pengalaman dari tindakan ini pada gilirannya juga akan membentuk pengetahuan atau teori dalam kasus-kasus tertentu.

Pada kuadran kedua adalah intruction leader. Intruction leader dibentuk dari kecukupan pengetahuan (more knowledge) dan keterbatasan pengalaman (lose experience). Keterbatasan pengalaman pemimpin sekolah akan membawa pada sikap intruction, yang hanya mampu memerintahkan sesuai dengan pengatahuan yang dimiliki (teks book), dan kurang dalam praksis-aplikatif dilapangan.

Pada kuadran ketiga adalah direction leader. Direction leader terbentuk dari kecukupan pengalaman (more experience) pemimpin, namun terbatas dalam pengetahuan (lose knowledge). Terbatasnya pengetahuan pemimpin sekolah akan membawa pada sikap direction atau mengarahkan yang dipimpinnya dengan berbekal pengalaman-pengalaman yang dimilikinya. Arahan-arahan yang diberikan bisa jadi bertentangan dengan aturan main organisasi.

Pada kuadran keempat adalah sceptic leader. Sceptic leader terbentuk dari terbatasnya pengetahuan dan pengalaman memimpin. Pengetahuan dan pengalaman yang tidaka dimikili seorang pemimpin membawa pada sikap skeptis, penuh curiga dan tidak memiliki arah organisasi yang jelas.

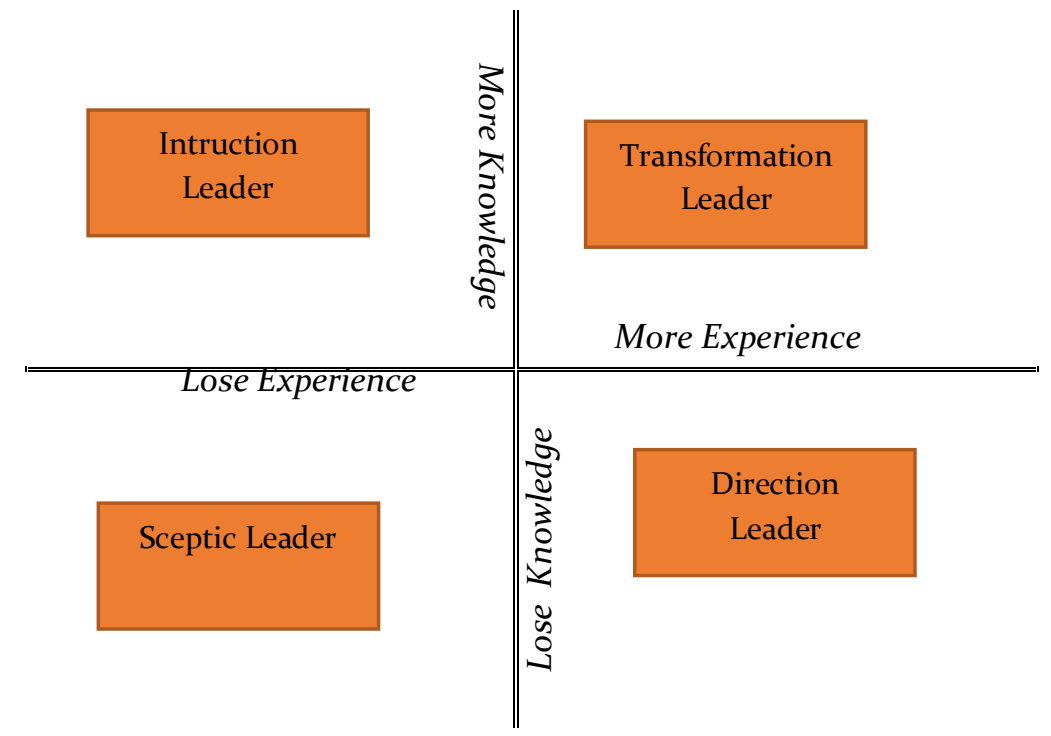

Gambar 2. Model kepemimpinan

\section{Kepemimpinan Transformasional di Sekolah Kelas Menengah Muslim Yogyakarta}

Model kepemimpinan transformatif terlihat cukup dominan pada sekolah kelas menengah muslim di Yogyakarta. Kepemimpinan transformasional adalah kemampuan seorang pemimpin dalam bekerja dengan dan atau melalui orang lain untuk mentransformasikan secara optimal sumber daya organisasi dalam rangka mencapai tujuan sesuai dengan target capaian yang telah ditetapkan. Sumber daya dimaksud dapat berupa SDM, fasilitas, dana, dan faktor-faktor eksternal keorganisasian.
Kepemimpinan transformatif berasal dari dua kata yaitu kepemimpinan (leadership) dan transformatif atau transformasional (transformative /transformational). Sadler mengungkapkan "transformational leadership is the process of engaging the commitment of employees in the context of shared values and shared vision." Dari pengertian tersebut ada tiga hal yang merupakan inti kepemimpinan transformasional, yaitu komitmen, berbagi nilai-nilai organisasi, dan berbagi visi organisasi. Menurut Bass (1985) "transformational leadership contains contains four components: charisma or idealized influence (attributed or behavioral), inspirational motivation, intellectual stimulation, and individualized consideration." 
Secara terminologis, istilah transformatif berasal dari kata to transform, yang berarti berubah atau mengubah (change), atau mengubah sesuatu menjadi bentuk lain. ${ }^{24}$ Jadi kepemimpinan transformatif adalah tindakan seorang pemimpin yang mampu mengubah dan menggerakkan sumber daya organisasi sehingga mencapai tujuan yang ditetapkan. Intinya adalah kemampuan seorang pemimpin yang mampu mengubah potensi organisasi menjadi energi nyata sebagai media mencapai tujuan.

Kepemimpinan transformasional di sekolah kelas menengah muslim ini terbentuk melalui dua kemampuan yang dimiliki yaitu, pertama, penguasaan pengetahuan (knowledge) seperti teori-teori organisasi, budaya organisasi, manajemen strategik, kepemimpinan, dan pengetahuan managerial lainnya. Pengetahuan ini umumnya didapat dari bacaan, diskusi, seminar, pelatihan, refleksi dan bacaan sebagai pengkaya pengetahuan. Dengan semakin luas pengetahuan dan wawasan seseorang pemimpin, maka semakin terbuka, fleksibel, inklusif, mudah menerima masukan (open minded), dan mampu mengolahnya menjadi pengetahuan baru.

Kedua adalah pengalaman. Pengalaman adalah sesuatu yang pernah dialami, dijalani, dirasakan, ditanggung. Pengalaman dapat memunculkan potensi seseorang. Sebuah potensi akan muncul seiring berjalannya waktu sebagai tanggapan terhadap bermacam-macam pengalaman. Jadi sebuah pengalaman sangat berhubungan dengan kemampuan dan kesediaan untuk terus belajar. Semakin banyak belajar, maka semakin banyak pula pengalaman yang akan didapat. Penggabungan antara pengetahuan dan pengelaman inilah yang akan membentuk teori.

${ }^{24}$ Abdul Kadim Masaong \& Arfan A. Tilome. (2011). Kepemimpinan Berbasis Multiple Intelligence: Sinergi Kecerdasan Intelektual, Emosional dan Spiritual untuk Meraih Kesuksesan yang Gemilang. Bandung: Alfabeta, Inc. Lebih lanjut juga lihat Imam Machali. (2018). The Handbook of Education Management, Teori dan Praktik Pengelolaan Sekolah/Madrasah di Indonesia. Jakarta: Prenadamedia Group, Inc.
Penguasaan pegetahuan (knowledge), dan pengalaman membentuk gaya kepemimpinan transformasional, dimana ia mampu mengembangkan nilai-nlai organisasi seperti kerja keras, disipin, semangat, motivasi, rasa memiliki dan tanggungjawab (sense of belonging and sense responsibility). Dengan pengalamannya tersebut, kepala sekolah mampu memprediksikan kemungkinan lembaga, dan secara cepat dapat mengambil keputusan-keputusan yang tepat dan strategis.

Pemimpin transformational setidaknya memiliki empat krakteristik yaitu (1) customized consideration, (2) intellectual stimulation, (3) inspirational motivation, dan (4) idealized influence. ${ }^{25}$ Customized consideration adalah karakter seorang pemimpin yang mampu memahami perbedaan individu anggotanya. Dengan modal memahami perbedaan setiap individu anggotanya tersebut, seorang pemimpin mampu membimbing dan melatih anggotanya sesuai dengan karakteristik dan potensinya, sehinngga dapat memaksimalkan kinerjanya untuk mencapai tujuan lembaga.

Intellectual stimulation adalah karakter pemimpin transformasional yang dapat menstimulasi bawahannya untuk mengerjakan tugas-tugasnya secara baik, efektif dan efisien. Selain itu memberikan kepercayaan terhadap bidang tugasnya untuk kreatif dan inovatif. Sehingga tujuan lembaga dapat tercapai dengan baik. Inspirational motivation berarti kemampuan memberi motivasi dan menginspirasi anggotanya untuk mencapai target atau standar yang telah ditetapkan. Dengan mendorong, menginspirasi dan memotivasinya maka anggota memiliki optimisme dan antusiasme, sehingga bersemangat menjalankan tugas yang diberikan. Idealized influence adalah wibawa atau kharisma yang dimiliki seorang pemimpin sehingga anggotanya dengan kesadarannya mejalankan perintah atau tugas-tugas yang diberikan. Kharisma seorang

${ }^{25}$ Maryam Mahdinezhad, Turiman bin Sunadi, Abu Daud bin Silong, an Zoharoh binti Omar. (2013). Transformational Transactional Leadership Performance of Academic Leaders. International Education Studies 6(11): 29-34. doi: 10.5539/ies.v6n11p29 
pemimpin transformasional dibangun dari pengetahuan, pengalaman, komitmen, loyalitas, tegas, dan sikap menghargai bawahan. Sehingga pemimpin selain menjadi panutan juga menjadi role model organisasi.

Modal pengetahuan (knowledge capital) dan modal pengalaman (exsperience capital) yang dimiliki oleh kepala sekolah tersebut menjadi modal penting dalam mengembangkan sekolah. Dengan modal tersebut kepala sekolah merumuskan visi kepemimpinananya (leadership vision), apa yang akan dilaksanakan, target apa akan dicapai, dan langkah-langkah apa yang akan ditempuh selama menjadi kepala sekolah. Visi kepemimpinan ini berbeda dengan visi lembaga. Visi kepemimpinan ini adalah target yang akan diraih oleh seorang pemimpin dalam rentang atau waktu ia menjadi pemimpin di sebuah sekolah. Visi kepemimpinan ini menterjemahkan visi lembaga dan mengoperasionalkannya dalam tindakan oraganisasi di bawah komando kepala sekolah. Untuk mencapai dan mewujudkan visinya, kepala sekolah menyusun rencana strategis. Dengan demikian apa yang akan dilakukan terencana dan memiliki roadmap yang jelas dalam mewujudkan visi lembaga.

Modal pengetahuan dan pengalaman kepala sekolah kelas menengah muslim di Daerah Istimewa Yogyakarta ini juga membawa keberanian untuk mengimplementasikan rencana strategi. Tidak ada jaminan bahwa rencana strategi yang dususun dengan baik dapat diimplementasikan dengan baik. Banyak terjadi kegagalan organisasi disebabkan oleh lemahnya eksekusi atau implementasi beragam rencana. Akhirnya visi, misi, tujuan dan program organisasi yang disusun dengan susah payah dan menghabiskan banyak dana hanya menjadi hiasan dinding, arsip, dan dokumen mati saja. Dalam hal ini pengalaman, pengetahuan dan kematangan memimpin dan berorganisasi memiliki peran sangat penting. Beberapa kepala sekolah kelas menengah muslim DIY telah mengenal dan memahami konsep dan strategi bagaimana megimplementasikan rencana strategik dengan konsep Quality Implementation (QI). ${ }^{26}$

$\begin{array}{ccr}{ }^{26} \text { Kevin } & \mathrm{Wu}, \quad(2010) . & \text { Quality } \\ \text { Implementation, } & \text { Kunci } & \text { Meningkatkan }\end{array}$

Penyebab lemahnya implementasi rencana strategik diantaranya adalah kepemimpinan yang buruk (bed leader), tujuan yang tidak jelas dan tidak menarik, tidak tahu apa yang harus dilakukan untuk mencapai tujuan, budaya organisasi yang buruk, dan kompensasi yang tidak efektif.

Langkah-langkah trasformasional yang dilakukan oleh pemimpin transformatif pada sekolah kelas menengah muslim di DIY menyusun secara partisipatif tujuan yang sangat jelas. Umumnya mengguakan rumus SMART. S untuk Specific (detail), M untuk Measureable (terukur), A untuk Attractive (sangat menarik), R untuk Reasonable (alasan yang kuat), dan T untuk Timeframe (kerangka waktu yang jelas). Kemudian fokuskan atau prioritaskan faktor-faktor kunci (key driver), dengan menentukan key drivers yaitu analisis keberhasilan di waktu lampau, analisis sumber penghambat utama, dan analisis kebutuhan stakeholders. Kemudian membangun budaya bersama, yaitu mengkondisikan tim untuk mampu mempergunakan kemampuan, kreativitasnya untuk melakukan sesuatu untuk meraih tujuan lembaga sebagaimana yang telah disepakati. Pertumbuhan yang berkelanjutan juga menjadi perhatian pemimpin transformasional sebab sebuah upaya (effort) anggota sangat dipengaruhi oleh motivasi, dan motivasi dipengaruhi oleh kompensasi (reward) yang didapatkan. Dengan prinsip ini pemimpin transformasional menekankan bahwa reward atau kompetensi yang akan diberikan tergantung pada prestasi dan apa yang telah diberikan (effort) untuk mencapai tujuan lembaga.

\section{PENUTUP}

Kesimpulan dari penelitian ini adalah bahwa model kepemimpinan sekolah kelas menengah muslim di Yogyakarta adalah kepemimpinan transformasional. Model kepemimpinan ini terbentuk melalui dua kemampuan yang dimiliki yaitu, pertama, penguasaan pengetahuan (knowledge) seperti teori-teori organisasi, budaya organisasi, manajemen strategik, kepemimpinan, dan

Komitmen Tim, Mengimplementasikan Strategi, \& Melipatgandakan Hasil. Jakarta: PT. Gramedia Pustaka Utama, Inc. 
pengatahuan managerial lainnya. Semakin luas pengetahuan dan wawasan seseorang pemimpin, maka semakin terbuka, fleksibel, inklusif, mudah menerima masukan (open minded), dan mampu mengolahnya menjadi pengetahuan baru. Kedua adalah pengalaman. Pengalaman sangat berhubungan dengan kemampuan dan kesediaan untuk terus belajar. Semakin banyak belajar, maka semakin banyak pula pengalaman yang akan didapat. Penggabungan antara pengetahuan (knowledge) dan pengalaman (eksperience) inilah yang akan membentuk kepemimpinan transformasional.

Pengetahuan dan pengalaman ini menjadi modal utama dalam mengembangkan sekolah. Dengan modal tersebut kepala sekolah merumuskan visi kepemimpinannya (leadership vision), apa yang akan dilaksanakan, target apa akan dicapai, dan langkah-langkah apa yang akan ditempuh selama menjadi kepala sekolah. Modal pengetahuan dan pengalaman kepala sekolah kelas menengah muslim di Daerah Istimewa Yogyakarta ini juga membawa keberanian untuk mengimplementasikan rencana strategi dengan onsep konsep Quality Implementation (QI).

\section{DAFTAR PUSTAKA}

Ali, Hasanuddin and Lilik Purwandi. (2016). Indonesia 2020: The Urban MiddleClass Millenials. Jakarta: Alvara Research Center, Inc.

Ali, Hasanuddin. and Lilik Purwandi. (2017). Millennial Nusantara, Pahami Karakternya, Rebut Simpatinya. Jakarta: Gramedia, Inc.

Anonim. Jumlah Sekolah, Guru, Dan Murid Madrasah Aliyah (MA) Di Bawah Kementerian Agama Menurut Provinsi, Tahun Ajaran 2005/2006-2015/2016 https://www.bps.go.id/statictable/2014/0 9/10/1534/jumlah-sekolah-guru-dan-mur id-madrasah-aliyah-ma-di-bawah-kemen terian-agama-menurut-provinsi-tahunajaran-2005-2006-2015-2016.html.

Anonim. Jumlah Sekolah, Guru, Dan Murid Madrasah Ibtidaiyah (MI) Di Bawah Kementrian Agama Menurut Provinsi Tahun Ajaran 2011/2012-2015/2016. https://www.bps.go.id/statictable/2015/0 9/10/1811/jumlah-sekolah-guru-dan-mu rid-madrasah-ibtidaiyah-mi-di-bawah-ke mentrian-agama-menurut-provinsi-20112012-2015-2016.html.

Anonim. Jumlah Sekolah, Guru, Dan Murid Madrasah Tsanawiyah (MTs) Di Bawah Kementrian Agama Menurut Provinsi Tahun Ajaran 2011/2012-2015/2016. https://www.bps.go.id/statictable/2015/0 9/14/1836/jumlah-sekolah-guru-dan-mur id-madrasah-tsanawiyah-mts-di-bawahkementrian-agama-menurut-provinsi-tah un-ajaran-2011-2012-2015-2016.html.

Anonim. Persentase Penduduk Daerah Perkotaan Menurut Provinsi, 2010-2035. https://www.bps.go.id/statictable/2014/0 2/18/1276/persentase-penduduk-daerahperkotaan-menurut-provinsi-20102035.html.

Antara and Mukafi Niam. Jumlah Lembaga Pendidikan Islam Di Indonesia Terbesar Di Dunia. http://www.nu.or.id/post/read/ 64871/jumlah-lembaga-pendidikanIslam-di-indonesia-terbesar-di-dunia.

Asian Development Bank. (2010). Key Indicators for Asia and the Pacific 2010. Philippines: Asian Development Bank, Inc.

Azra, A., Jamhari. (2016). Pendidikan Islam Indonesia dan Tantangan Globalisasi: Prespektif Sosio-Historis in Ncetak Muslim Modern: Peta Pendidikan Islam Indonesia, ed. Jajat Burhanuddin and Dina Afrianty. Jakarta: Rajawali Press, Inc.

Hasan, Noorhaidi, (2009). Islamizing formal education: Integrated Islamic school and new trend in formal education institution in Indonesia, RSIS Working paper, No 172, Singapore: Nanyang Technological University, Inc.

Iskandar, Jamaluddin. (2017). Keterampilan Manajerial Kepala Sekolah, Jurnal Idaarah, 1(1): 89-95. 
Junaidah. (2015). Kontribusi Pemimpin Pendidikan Dalam Meningkatkan Mutu Pendidikan Di Perguruan Tinggi. AlIdarah: Jurnal Kependidikan Islam 5(2): 75-99. Doi:10.24042/Alidarah.V5i2.784.

Machali, Imam dan Ara Hidayat. (2018). The Handbook of Education Management, Teori dan Praktik Pengelolaan Sekolah/Madrasah di Indonesia. Jakarta: Prenadamedia Group, Inc.

Machali, Imam. (2015). Rethinking Marketing Sekolah. EDUKASI, Jurnal Penelitian Pendidikan Agama dan Keagamaan 13(1): 1-14.

Maryam Mahdinezhad, Turiman bin Sunadi, Abu Daud bin Silong, an Zoharoh binti Omar. (2013). Transformational Transactional Leadership Performance ogf Academic Leaders. Interational Education Studies 6(11): 29-34. doi: 10.5539/ies.v6n11p29

Masaong, Abdul Kadim dan Arfan A. Tilome. (2011). Kepemimpinan Berbasis Multiple Intelligence: Sinergi Kecerdasan Intelektual, Emosional dan Spiritual untuk Meraih Kesuksesan yang Gemilang. Bandung: Alfabeta, Inc.

Miles, Matthew B. \& A. Michel Huberman. (1992). Analisis Data Kualitatif. Terj. Tjetjep Rohendi Rohidi. Jakarta, UI Press.
Ruslan, Heri. (tanggal, bulan, 2014). 10 Tahun JSIT Indonesia Bangun Pendidikan Lewat SIT. https://www.republika.co.id/ berita/pendidikan/eduaction/14/01/31/n0 8dcm-10-tahun-jsit-indonesia-bangunpendidikan-lewat-sit.

Salim, Felia, (2012). Financial Club Discussion: Indonesia's Middle Class, Inc.

Suyatno. (2015). Sekolah Dasar Islam Terpadu dalam Konsepsi Kelas Menengah Muslim Indonesia, Analisis Journal of Social Sience and Religion. 22(01).

The Organisation for Economic Co-operation and Development (OECD). (2010). Latin American Economic Outlook 2011: How Middle class is Latin Amerika? OECD publishing, Inc.

$\mathrm{Wu}$, Kevin. (2010). Quality Implementation, Kunci Meningkatkan Komitmen Tim, Mengimplementasikan Strategi, \& Melipatgandakan Hasil. Jakarta: PT. Gramedia Pustaka Utama, Inc.

Yuswohadi dan Kemal E Gani. (2015). 8 Wajah Kelas Menengah, Jakarta: Gramedia, Inc. 